\title{
The failure of contemporary law and regulation to keep pace with growing complementary medicine (CM) use: The significance of examining 'hidden' gaps in Australia's current regulatory and legislative infrastructure
}

\author{
David Sibbritt $^{1}$, Jenni Milbank ${ }^{2}$, Anita Stuhmcke ${ }^{2}$, Miranda Kaye $^{2}$, Isabel Karpin ${ }^{2}$, Jon Wardle ${ }^{1}$ \\ 1. Australian Research Centre in Complementary and Integrative Medicine, Faculty of Health, \\ University of Technology of Sydney
}

2. Faculty of Law, University of Technology Sydney

Complementary medicine $(\mathrm{CM})$, which includes a range of self-directed and practitioner-directed health practices (e.g., meditation and yoga, chiropractic, naturopathy) and products (e.g., herbal medicine, homeopathy, nutritional supplements), now constitutes a sizeable part of the Australian healthcare sector ${ }^{1}$. Despite the increasingly significant role of CM in Australian healthcare, it remains unclear how regulatory and consumer protections interface with this care. This lack of clarity is further compounded by the increasing integration of biomedical and complementary health approaches under the moniker of integrative medicine ${ }^{2}$.

Integrative medicine's combination of CM and conventional medicine approaches brings with it not only a blend of clinical and philosophical healthcare approaches, but also a blend of professional norms and standards, duties and precedents that complicate regulatory and legislative examination of this form of practice. Recently, the risks associated with CM products, and cases where unprofessional and negligent treatment by $\mathrm{CM}$ practitioners has resulted in deaths, personal injury and unethical practices, have been publicly profiled ${ }^{3}$, highlighting the failure of contemporary regulatory and legislative consumer protection measures to keep pace with the rise in $\mathrm{CM}$ use.

Lack of coherent regulatory or legislative mechanisms has forced consumer protection to be enacted through novel and often untested mechanisms. For example, failure of therapeutics goods or practitioner legislation to deal with misleading claims surrounding homeopathic vaccination required action via Australian Consumer Law, which is not often well-placed to deal with the nuances and 
priorities of health-specific legislation ${ }^{4}$. Governments have been hesitant to extend registration to any new health professions (including - but not limited to - CM professions) ${ }^{5}$, and instead use 'catch-all' legislation to target unregistered practitioners. However, this approach has brought with it the risk of regulatory chill in ensuring consumer protection in other areas that may not be adequately covered by current legislation ${ }^{6}$.

The regulatory environment is further complicated by the overlapping or shared jurisdiction of multiple regulators for certain $\mathrm{CM}$ products and practices: for example, advertising claims made by $\mathrm{CM}$ manufacturers may fall under the jurisdiction of differing statutory or self-regulatory authorities depending on whether a false claim has been made in-store, on printed advertising material, on television or online ${ }^{7}$. Furthermore, an ad-hoc approach to $\mathrm{CM}$ regulation has resulted in several inconsistencies and inefficiencies in consumer protection mechanisms. Although variable and substandard training of CM practitioners has been identified as an important consumer protection issue, government policies may have in part encouraged an active reduction in standards by subsidising training courses that do not even meet government requirements for recognition ${ }^{8}$.

Despite the lack of development in this area, the interface between CM and regulatory and legislative spheres is increasingly significant. Not only do CM issues represent a significant proportion of disciplinary actions against conventional health practitioners, but lack of regulatory attention around CM may allow practitioners previously prohibited as conventional providers to re-brand as CM providers ${ }^{9}$. There may also be significant economic consequences due to the lack of appropriate regulatory and legislative infrastructure around CM issues - the longest disciplinary case in Australian history (Chiropractic Board of Australia v. Hooper) involved unorthodox CM treatments, the complexities of which attributed in some part to the case's length, and many of the mistakes leading to the mishandling of the Pan Pharmaceuticals recall (historically remembered as a CM event, but actually initiated due to issues with conventional pharmaceutical manufacturing) were largely the result of details of regulatory provisions simply being non-existent for CM compared to conventional products $^{10}$. 
$\mathrm{CM}$ is generally defined as those practices not traditionally associated with biomedical practice or the conventional medical curriculum ${ }^{11}$. This definition - one of exclusion and convenience rather than one of systematic and coherent codification - means that CM often sits outside the regulatory and legal structures that exist for other, more conventional, health practices. CM use is a ubiquitous aspect of an increasingly consumer-driven model of healthcare delivery, and plays an increasingly prominent role in the Australian health sector. Yet a review of the literature reveals there is limited doctrinal and empirical research investigating the quality and integrity of protections for consumers in light of the high levels of use of CM and its significant role in healthcare in Australia.

This absence of critical and rigorous examination often means that questions around CM issues are increasingly interfacing with regulatory and legislative structure ill-equipped to deal with CM matters ${ }^{9}$. Despite the large number of Australian consumers choosing CM products and services, CM remains a practice that is marginalised within much of the Australian healthcare community, with the regulatory and legislative consumer protection mechanisms for $\mathrm{CM}$, and the relationship between CAM consumers, practitioners, manufacturers and regulators and the regulatory and legislative environment, virtually undocumented. The controversial (and marginalised) nature of CM can also bring with it ideological opposition to "recognising" CM practices through traditional regulatory mechanisms and safeguards, with debate around the topic of legislative and regulatory requirements of CM often remaining polemic, polarised and opinion-based ${ }^{12}$. Given the increasing role of integrative medicine, however, there is an urgent need for further empirical research into whether current regulatory arrangements provide appropriate consumer protection, to determine the consumer protection measures that are needed, and to investigate the role the CM industry perceives that regulation plays in the management of legal risk.

Although the Australian health regulatory framework is generally well developed, the integration of $\mathrm{CM}$ within that framework remains problematic. Very little is currently known about the legal and regulatory risks associated with what $\mathrm{CM}$ practitioners and manufacturers do in their practice and the impact on consumers, making it difficult to develop regulatory and legislative provisions that are both effective and workable. As such, there is an urgent need for a greater understanding of the current 
interface between CM and Australian society at all levels, including gaps which exist in the regulatory and legislative domains. Evidence-based, efficient and effective legislative and regulatory reform requires that new developments be focused on $\mathrm{CM}$ consumer needs, addressing identified legal risk issues and designed to provide improvements in health consumer protection, necessitating the significance and importance of further work in this area.

\section{References}

1. Reid R, Steel A, Wardle J, Trubody A, Adams J. Complementary medicine use by the Australian population: a critical mixed studies systematic review of utilisation, perceptions and factors associated with use. BMC Complement Altern Med 2016; 16(1): 176.

2. Australasian Integrative Medicine Association. Best practice for integrative medicine in Australian medical practice. Advances in Integrative Medicine 2014; 1(2): 69-84.

3. Wardle J, Weir M, Marshall B, Archer E. Regulatory and legislative protections for consumers in complementary medicine: Lessons from Australian policy and legal developments. European Journal of Integrative Medicine 2014; 6(4): 423-33.

4. Weir M, Wardle J, Marshall B, Archer E. Complementary medicine and consumer law. Competition and Consumer Law Journal 2013; in press.

5. Wardle JL, Sibbritt D, Broom A, Steel A, Adams J. Is Health Practitioner Regulation Keeping Pace with the Changing Practitioner and Health-Care Landscape? An Australian Perspective. Frontiers in public health 2016; 4: 91.

6. Wardle J. Holding unregistered health practitioners to account: an analysis of current regulatory and legislative approaches. J Law Med 2014; 22(2): 350-75.

7. Harvey K, Korczak V, Marron L, Newgreen D. Commercialism, choice and consumer protection: regulation of complementary medicines in Australia. Medical Journal of Australia 2008; 188(1): 21-5.

8. Wardle J, Steel A, Adams J. A review of tensions and risks in naturopathic education and training in Australia: a need for regulation. J Altern Complement Med 2012; 18(4): 363-70.

9. Freckelton I. Unscientific health practice: legal and ethical implications. J Law Med 2011; 18(4): 645-

68.

10. Wardle J, Adams J. Indirect and non-health risks associated with complementary and alternative medicine use: An integrative review. European Journal of Integrative Medicine 2014; 6(4): 409-22.

11. Adams J, Andrews G, Barnes J, Broom A, Magin P, editors. Traditional, Complementary and Integrative Medicine: An International Reader. Buckinghamshire: Palgrave Macmillan; 2012.

12. FlAtt J. Critical discourse analysis of rhetoric against complementary medicine. Creative Approaches to Research 2013; 6(2): 57. 